\title{
Schedule of Activities
}

National Cancer Institute

\section{Source}

National Cancer Institute. Schedule of Activities. NCI Thesaurus. Code C132349.

A planned list of clinical trial activities to include interventions, assessments, and study administrative activities. 